\section{P2-549 EPIDEMIOLOGICAL ASSOCIATIONS OF HEARING IMPAIRMENT AND HEALTH AMONG A NATIONAL COHORT OF 87134 ADULTS IN THAILAND}

doi:10.1136/jech.2011.142976m.76

${ }^{1}$ V Yiengprugsawan, ${ }^{*}{ }^{1}$ A Hogan, ${ }^{1} \mathrm{D}$ Harley, ${ }^{2}$ S-A Seubsman, ${ }^{1}$ A Sleigh. ${ }^{1}$ Australian National University, Canberra, Australia; ${ }^{2}$ Sukhothai Thammathirat Open University, Nonthaburi, Thailand

Background Socioeconomic and epidemiological effects of hearing impairment have been investigated in rich countries. But in most of the developing world, including middle income countries of Southeast Asia, evidence is still quite scarce. This study examines the association between hearing impairment and health outcomes in Thailand.

Methods Data derived from a cohort of 87134 Open University adults residing throughout Thailand. Multivariate logistic regression was used for analysis reporting ORs and CIs. Population attributable fractions were estimated from exposure prevalence among controls and ORs.

Results Approximately $8.5 \%$ of cohort members reported trouble hearing, $0.13 \%$ reported being deaf, with increasing prevalence associated with older age. After adjusting for age and sex, poor selfassessed health was strongly associated with some trouble hearing $[\mathrm{OR}=2.70,95 \%$ CI 2.48 to 2.93$]$ and deafness $[\mathrm{OR}=3.08,95 \% \mathrm{CI}$ 1.73 to 5.50$]$. Poor psychological health was also strongly associated with some trouble hearing [OR=2.25, 95\% CI 2.12 to 2.39] and deafness $[\mathrm{OR}=2.43,95 \%$ CI 1.56 to 3.77$]$. Among the cohort the Population Attributable Fractions (PAF) for hearing impairment was $12.9 \%$ for poor self-assessed health, $9.8 \%$ for poor psychological health, $3.3 \%$ for metabolic disorders, and $4.1 \%$ for cardiovascular conditions. Almost all disease in the population was associated with the group with some trouble hearing because the number was much greater than the deaf group.

Conclusions Hearing loss in Thailand is common and strongly linked to several adverse health outcomes. There needs to be more attention on hearing impairment with regular check-ups and early detections. Psychological and medical counselling could help the hearing impaired to adopt strategies to prevent the various associated diseases.

\section{P2-550 EPIDEMIOLOGICAL ASSOCIATIONS OF VISION IMPAIRMENT AND HEALTH AMONG A NATIONAL COHORT OF 87134 ADULTS IN THAILAND}

doi:10.1136/jech.2011.142976m.77

${ }^{1} \mathrm{~V}$ Yiengprugsawan, ${ }^{1}$ S-A Seubsman, ${ }^{2} \mathrm{~A}$ Sleigh. ${ }^{1}$ Sukhothai Thammathirat Open University, Nonthaburi, Thailand; ${ }^{2}$ Australian National University, Canberra, Australia

Background To date, over 300 million people worldwide live with low vision and blindness from all causes, which imposes social and economic burdens on individual and families. This study examines the association between vision impairment and health outcomes in Thailand.

Methods Data derived from a national cohort of 87134 adults residing throughout Thailand. We report ORs from logistic regression as well as Population Attributable Fractions (PAFs) linking vision impairment to an array of health and psychological outcomes.

Results Approximately $28 \%$ of the cohort members reported refractive errors and about $8 \%$ had uncorrectable vision impairment. Awareness of refractive errors was associated with higher income and urban residence. Both types of vision impairment were positively associated with poor self-assessed health (age-sex adjusted ORs ranging from 1.50 to 2.18) and poor psychological health (age-sex adjusted ORs ranging from 1.35 to 1.86). PAFs show that correctable and uncorrectable vision impairment explain respectively $12.3 \%$ and $8.5 \%$ of poor self-assessed health, $8.9 \%$ and $6.3 \%$ of poor psychological health, and $3.5 \%$ and $3.6 \%$ of falls in the last year.

Conclusions We have found associations between vision impairments and various adverse health outcomes along with socioeconomic gradients for access to refractive corrections. Refractive error is the easiest to detect by regular eye check ups. Incorporating early detection and prevention at the primary healthcare will help to promote the eye health of Thais. 